\title{
In the Era of Big Data, School Enterprise Cooperation, Production and Education lintegration Build a Community of Common Destiny
}

\author{
Li Jiao ${ }^{1, *}$, Hui $\mathrm{Li}^{2, *}$ \\ ${ }^{1}$ Qilu Medical University, No.246, West Outer Ring Road, Zibo, Shandong255300 \\ ${ }^{2}$ Shandong Institute of Commerce \&Technology; No 4516, Lvyou Road, Jinan, Shandong 250103,china
}

\begin{abstract}
This paper is to construct the modern apprenticeship talent training mode of "intercommunication, integration, and advancement", explore the road of school enterprise joint construction of Industrial College, and serve the national strategy and industrial development needs. This paper specialty and industry drive each other, seize the opportunity of a new round of scientific and technological revolution and industrial transformation, closely connected with the national strategy, deeply cooperate with industry-leading enterprises, face the new economy characterized by new industry, new technology, new business form, and a new mode, closely follow the needs of the era of "cloud, material, big, intelligent and mobile", and integrate industry, enterprise, and school in-depth, so as to create the fate of school and enterprise Community.
\end{abstract}

\section{Introduction}

Under the guidance of the national strategy, the big data industry is showing a blowout growth and fast updating of big data technology. Data thinking and data technology brought by big data technology are reconstructing many fields and industry ecology including education. The rise of big data strategic emerging industries is an important opportunity for local colleges and universities in China to explore in-depth integration mechanisms of production and education, innovate education forms, and form resonance with the development of the big data industry.[1]

\section{Constructing the modern apprenticeship training mode of "intercommunication, integration, and advancement"}

Local colleges and universities cooperate with leading enterprises in the industry and leading enterprises in pillar industries to explore the modern apprenticeship talent training mode of "communication, integration, and advancement", and cultivate compound and innovative modern technical and skilled talents through the integration of production and education.[2]

Intercommunication: the cooperative enterprise is responsible for providing work projects and part-time teachers (Masters) of the enterprise, and jointly designing the task-based training mode with the school to meet the post requirements. The school and enterprise cooperate to develop a batch of new loose-leaf teaching materials or work manual type teaching materials with basic knowledge, living cases, and skills. [3]

It realizes the materialization of the learning scene, the reality of learning tasks, the visualization of learning effect and the experience of learning activities, and conveys and teaches the obscure professional knowledge and skills in an explicit way. Through the rotation training, fixed position training, and comprehensive training based on real projects, the students can basically complete the growth from students, apprentices who can perform tasks, apprentices who can innovate and apply, to prospective employees and employees.

Integration: first of all, cross-professional rotation learning based on real projects of cooperative enterprises is cross integrated to cultivate students' overall understanding of the post and general technical skills; secondly, based on the organic integration of cooperative enterprise project learning and service cooperative enterprise, the ability of teachers and students to connect posts is improved, and the cost of enterprise trial and error is reduced; thirdly, the progressive integration of innovation and entrepreneurship ability and professional teaching In order to improve the students' ability of innovation and application of technical skills in economic work, the two abilities should be developed in parallel.[4] Advanced: design the training mode of four stages of skill improvement. The first stage is mainly to cultivate students'; Post basic technical skills through project-

*19980181@sict.edu.cn 
based learning combined with courses; the second stage is to cultivate students' ability to solve complex post scene problems by relying on cooperative enterprises through job rotation and fixed post-training based on actual projects; the third stage is to carry out post following practice by relying on enterprise/skill master studio to consolidate students' technical skills; the fourth stage is to rely on cooperative enterprises to carry out post following practice relies on cooperative enterprises and school resources to improve students application ability of new technology and new mode and innovation and entrepreneurship awareness; finally, it will transfer the skilled and quasi employees to the enterprise for internship andemployment.

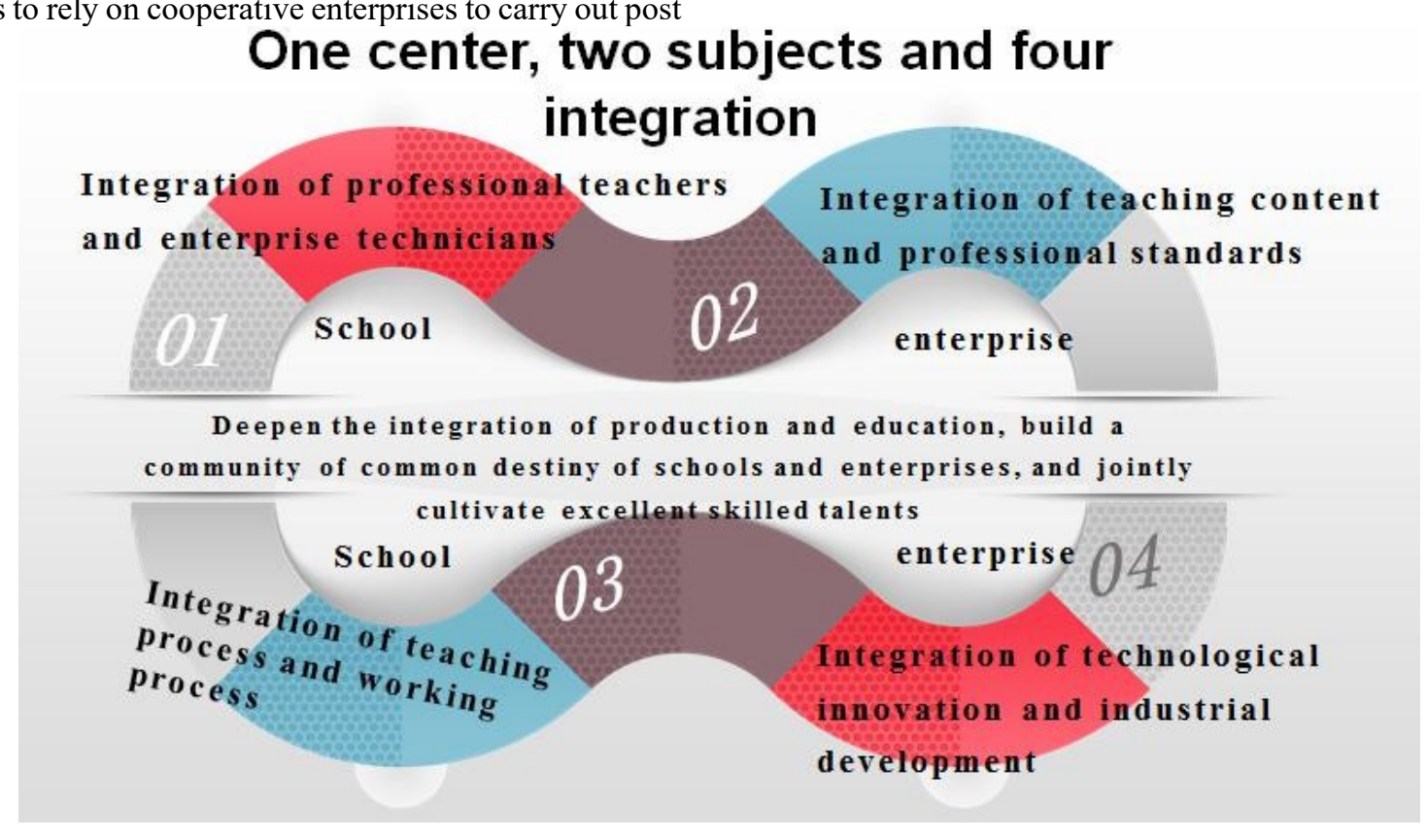

Figure 1. "One center, two subjects, four integration" framework of industry educationintegration

\section{Build a framework of "one center, two subjects and four integration" for Industry and education integration}

One center: through school enterprise cooperation, it aims to promote the in-depth integration of production and education, build a community of common destiny between schools and enterprises, and jointly cultivate excellent skilled talents.

Dual subject: in the new era, the construction of vocational education industry education integration community of destiny, local colleges, and enterprises are both the main body, we should realize that vocational education is the common cause of schools and enterprises, industry, and education are highly unified and inseparable.

Four Integration: to realize the deep integration of school full-time teachers and enterprise technicians, the deep integration of teaching content and professional standards, the deep integration of teaching process and working process, and the deep integration of scientific and technological innovation and industrial development.[5]

\section{Explore the co-construction of Industrial College and build a community of shared future of school and enterprise}

Establish the management system and operation mechanism of the industrial college, improve the council system, attract the representatives of industry-leading enterprises and small and medium-sized enterprises to participate in the school governance, and regularly hold council meetings; build a three-dimensional and open new relationship among the government, association enterprises, and schools, solidify the support of all parties through organizations, systems, and activities, and establish the government guidance and government enterprise School Association The "integration of industry and education, school enterprise integration" mechanism and community of destiny. The president's responsibility management mode under the leadership of the Council is adopted. [6]

The main tasks and implementation subjects of the two sides are clear. Through the construction of an enterprise studio, innovation base, and practice base, the high-quality resources of all parties are quickly absorbed and gathered. In the industry development direction, industrial competitiveness and development planning, industrial policy and enterprise development strategy, technical service and cultural guidance, high-end 
technology. In addition, we should build a regional center for the integration of production and education, comprehensively implement the modern apprenticeship and task-based training mode, and substantially promote collaborative education.

\section{The problems to be solved urgently are as follows:}

(1) How to realize the identity of both sides of production and education from the separation of supply and demand to strategic partners

In the past, the problems of "integration but incompatibility" and "integration without depth" between local universities and enterprises have been unable to be effectively solved. The important reason is that the identity of both sides of production and education is in the state of separation of supply and demand. Only by highly integrating and deeply cooperating, can we give full play to the role of technical talents in supporting the development of modern industry, and enable enterprises to fully enjoy the "talent dividend", so as to achieve better and faster development. From the perspective of the growth of technical talents, the learning of theoretical knowledge can be completed through school teaching, and the training of technical skills must be carried out in the actual working situation.

(2) How to promote the value pursuit of both sides from project cooperation to sustainable development

In the era of big data, in order to deepen the integration of industry and education and build a community of shared destiny for vocational education integration, we must break through the current situation that traditional integration of production and education is limited to project-based cooperation, build a pattern of integrated development of school and enterprise, and promote the value pursuit of both ends of production and education towards sustainable development. [7]

It should include two aspects: first, local universities and industrial enterprises should establish an integrated organizational form of "you have me, I have you". The integration of production and education should not only be reflected in the level of cooperation of each project but also should be deep into the cross integration level of the organizational system. Relying on the project of integration of production and education, the two sides of school and enterprise should continue to carry out integrated construction in terms of organizational culture, management system, and behavior mode, so as to build an integrated organizational form of deep integration of school and enterprise, so as to provide a strong organizational guarantee for resource sharing and complementary advantages of both sides. Second, local universities and industrial enterprises should establish a long-term mechanism of cohesion and common development[8].

\section{Conclusion}

The integration of industry and education has become the new normal of China's higher education reform. Deepening the integration of industry and education and promoting the organic convergence of education chain, talent chain, and innovation chain are important measures to promote education priority development, talent led development, industrial innovation development, and high-quality economic development. It is a strategic path for education to serve economic and social development and national revitalization in the era of big data.

\section{Acknowledgments}

1. The project of the 13th five-year plan of Education \&Science in Shandong Province in 2020 ---the Practical Research on the Integration of Production and Education in Local Colleges and Universities in Shandong Province; (Project No. 2020ZC240).

2. The project of the 13th five-year plan of Education \&Science in Shandong Province in 2020 -- Research on the innovation of Higher Vocational English Teaching Mode based on OBE Concept; (Project No. 2020WGYB011).

3.The Teaching Reform Project of Shandong Vocational Education in Shandong Province in 2017: "Research and Practice of Innovation and Entrepreneurship Education for Higher Vocational Students in the Resource Synergy Perspective" (Project Number: 2017170).

4.The Research Project of Teaching Reform in Shandong Undergraduate Colleges and Universities of

Shandong Education Department in 2018: "Shandong Province University Students' Innovation and Entrepreneurship Education and Practice Research Under Internet Plus Background" (Project Number : M2018X097).

5.China Association of Higher Education 2020"Research on Higher Vocational Education" special project: "The Construction of Double Qualified Teachers Team in Vocational Colleges under the Background of" Double High Program "; (Project No.: 2020GZYB10).

6.Research project of Humanities and social sciences of Shandong Institute of Commerce and Technology --Research on the Professional Development Path of" Double Qualified "Teachers in Higher Vocational Colleges under the Background of "Double High Program "(Project No. 2020A205).

7.The Project of 12th five years' Education \&Science plan of Shandong Province in 2015: A Study on the Application of Experiential Teaching in Five Year English Teaching(Project No.:CGW15010).

\section{References}

1. Jing $Z$ and Jinfeng Y 2017 Report on deepening the integration of industry and education in modern vocational education with Chinese characteristics 
since the 18th National Congress of the Communist Party of China J. Vocational and technical education 24 pp 45-52.

2. Huashan Z 2017 Interest conflict and balance mechanism construction in modern apprenticeship school enterprise cooperation J. Education and occupation 23 pp 17-23.

3. Xiaokun L and Peng L 2018 Strategies and Thoughts on promoting the integration of industry and education in local colleges and Universities -Based on the analysis of Wenzhou University $J$. Journal of National Institute of education administration 4 pp 53-57.

4. Cuixiang S 2018 The new mission of the new era: Policy Analysis on the integration of production and education $J$. Education and occupation 18 pp 11-17.

5. Luting M and Xiaoxin S 2019 Mode reform of Higher Vocational Education in the new era. Journal of Jishou University: Social Science Edition 2 pp 70-77.

6. Song H and Baoge Z 2019 Research on the path of connotative development of Higher Education under the background of industry education integration $J$. Education exploration 1 pp65-69.

7. Yanlin M 2018 School running patterns in the era of industry education integration $2.0 \mathrm{~J}$. China higher education $2 \mathrm{p} 22$.

8. Peiyun Z, Ting G, Zhang $\mathrm{S}$ and et al 2019 Reflections on the "dual" education of school enterprise integration of production and education $J$. Journal of State Grid Institute of technology 4 pp 59-61. 